\title{
Using the technology acceptance model in understanding citizens' behavioural intention to use m-marketing among Jordanian citizen
}

\author{
Mohammad Mahmoud Alzubi \\ Maged Mustafa Al-Dubai \\ Mazen Mohammed Farea \\ Al-Madinah International University, Malaysia
}

\begin{abstract}
Keyword
M-marketing, Trust Factor, Perceived ease of use, Perceived usefulness, Technology Acceptance

Model,
\end{abstract}

\begin{abstract}
This study aims to identify and understand factors that affect to acceptance $M$-marketing among Jordanian citizen. This study integrates technology acceptance model (TAM) with Trust factor. The primary data were collected from 1950 valid questionnaires, which were distributed, to random Jordanian citizen in three cities. The analyses of the gathered data employed the Partial Least Squares Structural Equation Modeling (PLS-SEM). The validity of the final overall model was evaluated using the statistics and acceptable fit of the measurement model to the data has been demonstrated. Based on the outcomes, the factors with the highest direct effect on Intention to use M- marketing appeared to be Attitude toward using $M$ marketing, while the factor with the highest indirect effect on Intention to use M- marketing appeared to be Compatibility. The main findings of the study are: trust factor has a positive and significant impact on perceived ease of use and perceived usefulness. Ease of use and perceived usefulness has the stronger impact on customers' attitude, which in turn influences customers' intention to use M-marketing services.
\end{abstract}

Corresponding author: Mohammad Mahmoud Saleem Alzubi

Email addresses for corresponding author: mohammad.mahmoud@mediu.edu.my

First submission received: 26th April 2017

Revised submission received: 9th June 2017

Accepted: 8th August 2017

\section{I.1 Introduction}

The current time regards mobile as an integral part of consumers. The swift global expansion in the sales and usage of Smartphone turns mobile marketing into a trending medium of marketing in today's world. Park and Salvendy (2012) reported the popularity of mobile phones over other mediums such as televisions and laptops, and this has made mobile phone advertising an expanding phenomenon as well. Mobile marketing allows freedom to point to certain consumers according to location, personalization of content, aside from offering a scope for interaction. ComReg (2014) reported that in 2013, almost all (97\%) Irish consumers owned a mobile phone when compared to $69 \%$ who owned landlines. Within the marketing communications, mobile Marketing is now a global trend. This, according to Shankar and Yadav (2010), owes to its distinct characteristics including ultra-portability, locationsensitivity and channel independent. In the context of Jordan, users of Smartphone have grown in number. In fact, a report by Alrai Newspaper stated that by 2016, the ownership of Smartphone was at $75 \%$. Then, in a report on the clothing retailing trends in Jordan released in December 2016, customers demand in-store innovative technology so that their experience of shopping could be improved. Over the years, the trend has grown; consumers now attempt to interact with retailers and brands using technologies including GPS, QR codes, Mobile websites as well as the applications of Mobile social networking. Mobile devices can become a gateway in the establishment of a relationship between a consumer and a retailer.

\section{I.2 Literature review}

Internet is now a valuable marketing platform for domestic and international transaction after it has become a global interconnection network for information sharing and delivering. According to A.T. 
Kearney (2015) reported the growth of retail e-commerce reaching US 840 billion in 2014. The amount, according to the author, surpassed the sales of US 695 billion in the preceding year (2013) and it was projected to reach US 1506 billion in 2018. As sales are continuously increasing, it is clear that e-commerce has large market potential. Powerhouses in the e-commerce arena including Alibaba, Tenement, Amazon and Groupon have been successful and they become an example for corporates to switch from the traditional business to the brick-and-click type. Albeit the global flourishing of e-commerce, Malaysia's ranking had fallen in 2015, below its 30th position in the Top 30th Global Retail E-Commerce ranking (A.T. Kearney, 2015).

Consumer behavior has changed over the decade and this necessitates the retailers to attempt to comprehend the virtual consumers in terms of their psychology. Decoding the online consumer behavior is hard and the fact that there is no physical interaction during the transactions makes the problem more complicated (Jiang, Chen, \& Wang, 2008). IPSOS Open Thinking Exchange (2012) reported that more than half $(56 \%)$ of the respondents from 24 countries would rather do their shopping at a traditional store as opposed to the online stores (Marketing Charts, 2012). For instance, in the United States, which is one example of a developed country, $63 \%$ of its consumers reported that they would do a survey on the internet prior to making a purchase and yet, only half of them would actually purchase online (NPD Group, 2011).

People might have already been aware of the term Internet several years earlier (Hofacker, 2001). The Internet, which was created by computer software, comprises the overall devices interconnected by the Internet Protocol. As indicated by Rowley (1996), initially, the Internet was an academic network. However, after its usage started growing in business, the Internet is now accessible to small colleges, small businesses and libraries on a global scale. With respect to e-commerce, IBM described it as business to vendors, to customers, to employees, and to suppliers via Intranet, Extranets and in Internet ECommerce, Internet is crucial as its main medium. Therefore, countries pursuing improved economy via e-commerce usage have to adopt the Internet and be prepared for both its advantages and disadvantages. Meanwhile, a number of factors causes the success and failure of e-commerce. In relation to this, the factor of trust could have potential in influencing users' intention to engage in online transaction. Thus, this factor is investigated in this study.

\section{I.3 Theoretical Background}

The Technology Acceptance Model (TAM) can assist in the comprehension about what determines user acceptance of M-marketing. Therefore, this model is highlighted as below: Davis (1986) created the well-known technology acceptance model (TAM). This model relates to technology acceptance and use. TAM is a theoretical model that contributes to the explanation and foretelling of user behavior of information technology (Legris, Ingham, \& Collerette, 2003). This model is an influential extension of theory of reasoned action (TRA) by Ajzen and Fishbein (1980). TAM describes the reason a user accepts or rejects information technology by its adaptation of TRA (Davis, 1989). Using this model, researcher has a basis with which the way external variables affect belief, attitude, and intention to use is traceable. The two cognitive that TAM posits are perceived usefulness and perceived ease of use. TAM posits that the actual usage of a technology system by an individual is affected directly or indirectly by the behavioral intentions, attitude, perceived usefulness of the system, and perceived ease of the system of the user. The model also suggests that external factors influence intention and actual usage by way of mediated effects on perceived usefulness and perceived ease of use.

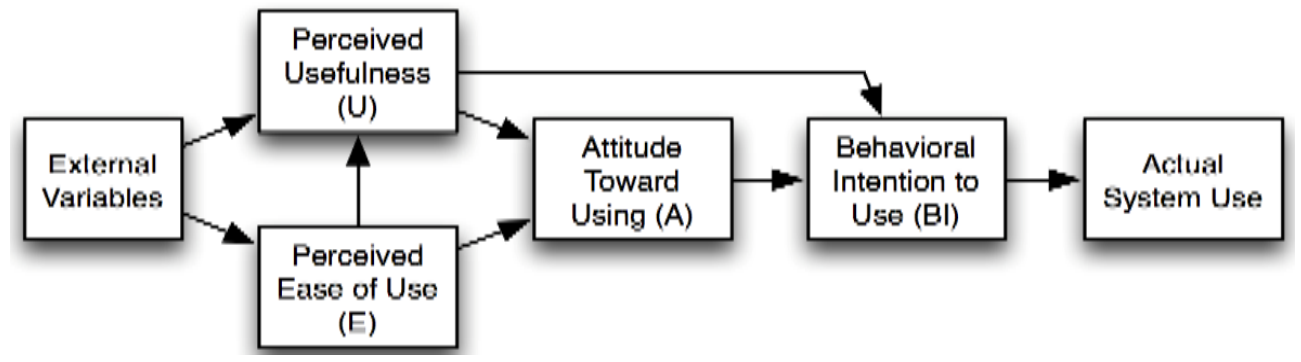

Figure 1: The original TAM (Davis, 1989). 


\section{I.4 Research Model Factors}

A research model grounded on Davis's (1989) Technology Acceptance Model (TAM) with the inclusion of one more factor is proposed in this study. This model will be utilized in the examination of the factors that affect users' acceptance of M-marketing in Jordan. The following comprises the discussion on the constructs of the proposed model.

The technology acceptance model or TAM was created for describing the determining factors of user acceptance in a vast range of computing technologies of end-user (Davis, 1986). Tung et al. (2014) mentioned this model as grounded on the theory of reasoned action or TRA proposed by Ajzen and Fishbein (1980). In addition, considering that TRA is a well-established model, it has been used by numerous scholars in numerous domains to provide explanation and prediction on human behaviour.

The first created TAM included five components: perceived ease of use (PEOU), perceived usefulness (PU), attitude toward using (ATU), behavioral intention to use (BI), and behaviour system use. In detail, PEOU signifies the extent to which a user feels that the utilization of certain service would be effort free, while PU signifies the extent to which an individual feels that the utilization of certain system would lead to improved performance of his or her job (Davis, 1989). PEOU and PU are regarded as the two most instrumental factors for system use. Liu and Han (2010) in fact stated that PEOU and PU are the primary beliefs leading to user acceptance of information technology. On the other hand, ATU directly foretells BI of the users. As from that,

Extensive research over the past decade provides evidence of the significant effect of perceived ease and perceived usefulness of use on usage intention, either directly, or indirectly, through its effect on perceived usefulness (Davis, 1989; Venkatesh and Morris, 2000).

\section{Perceived Trust}

As suggested by several researches, lack of trust in online businesses prevents many people from using the online services (Wu, \& Chen 2005). User's trust is feeling secure and confidence about depending on a service. Meanwhile, Gefen (2000) stated that in the settings of e-commerce, familiarity, which comprises of an awareness of what, why, where, and when other parties do what they do, also contributes to trust. In addition, as suggested by past authors, the feeling of trust is formable via interactions. Meanwhile, in M-marketing, personal information privacy and concerns on data security are found to be the influencing factors for citizens' lack of trust in online technology.

In respect to privacy, Benassi (1999) reported this factor as the leading Internet issue that consumers are facing. Many consumers remain doubtful when it comes to transmitting private information through this open electronic network, specifically financial information. Still, online commerce customers usually need more reassurance of privacy protection and greater degree of control over the releasable personal information (Khalifa \& Shen, 2006).

The major factors contributing to trust in mobile marketing are privacy and security. This extends to electronic commerce (Cheng et al., 2006). Wang et al., (2003) argued that information privacy is vulnerable on the internet and can lead people away from using IB and online financial transactions

\section{I.5 Research Framework and Hypothesis}

The focal point of this study is the viewpoint of individual. Based on the TAM model, this paper attempts to provide prediction on mobile marketing intention of users in online marketing. This study attempts to ascertain if the original constructs of TAM namely perceived usefulness, Perceived ease of use impart impact on mobile marketing. The reason is that Perceived usefulness directly influences user behavior while the impact of trust on mobile marketing intention is worthy to be aware of. As such, the construct of trust is also included in the research model. 


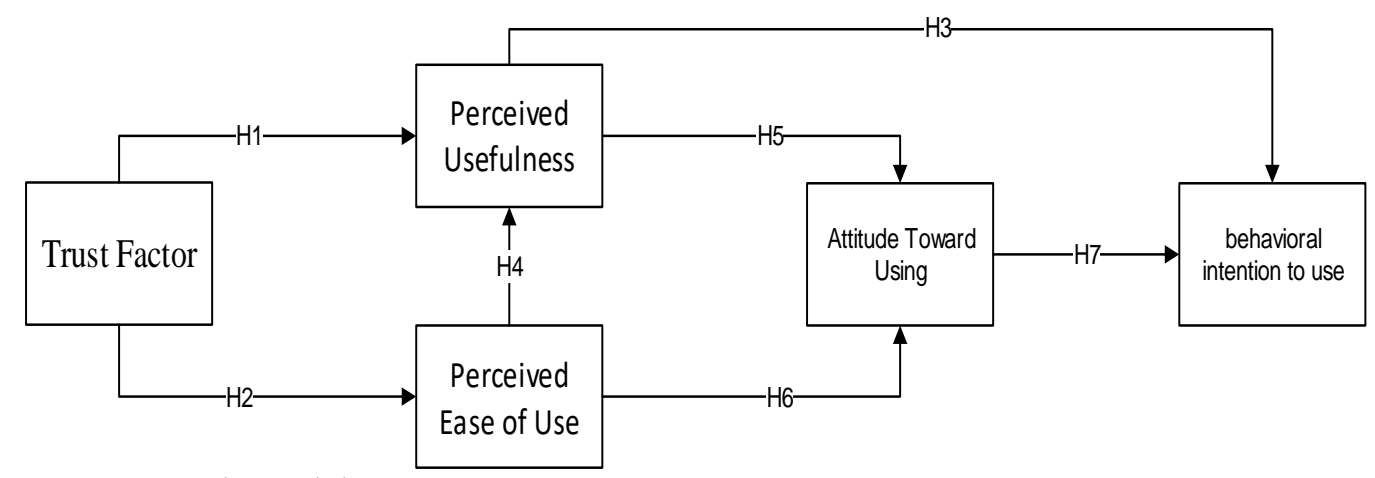

Figure 2: Research Model

\section{Research Hypothesis}

H1: Trust factor has a significant positive relationship with perceived usefulness in the use of MMarketing.

H2: Trust factor has a significant positive relationship with perceived ease of use to use M- Marketing.

H3: Perceived usefulness has a significant positive relationship with behavioral intention to use MMarketing.

H4: Perceived ease of use has a significant positive relationship with perceived usefulness to use MMarketing.

H5: Perceived usefulness has a significant positive relationship with attitude toward using to use MMarketing.

H6: Perceived ease of use has a significant positive relationship with attitude toward using to use MMarketing.

H7: Attitude toward Using has a significant positive relationship with use behavior to use M- Marketing.

\section{I.6 Questionnaire Development}

This study employed a questionnaire that is based on the available literature on TAM and trust (e.g., Davis. 1989; Chen et al., 2004; Venkatesh et al., 2003; Lu, Zhao, \& Wang, 2010; Wu, Chen, \& Chung, 2010) with mobile marketing in consideration. The construction of the items was according to the instruments employed by the past scholars. This would reflect the general dispositions of consumers towards behavioral intentions. As the respondents of this study were Jordanians, translation was made to the original instrument, from English to Arabic. The questionnaire was finalized after the repeated translation processes. A five-point scale was used to evaluate each item. The scale ranges from 1 (strongly disagree) to 5 (strongly agree).

\section{I.7 Research Methodology}

This research employed 1950citizens aged 18 and above enrolling in among Jordanian citizen as respondents. As for data, they were obtained online (online questionnaires at www.surveyshare.com). There is only one part to the questionnaire. This one part contains items, which represent several constructs. The 5-point scale was chosen for measuring the acceptance level of users. In order to measure the association between the six primary factors and behavioral intention to use M- marketing in Jordan, this study utilized regression analysis. This study attempts to construct an integrated framework with the capacity of measuring the citizen s' readiness to interact with M-marketing. In the investigation of these citizen s' readiness, validation to the trust factor with Technology Acceptance Model (TAM) has to be performed.

\section{A. Instrument Development}

The construction of the items was for determining the respondents' awareness of the online access to the M-marketing. Minor modification was made to the questionnaire based on respondent'scomments. At the same time, the readability and validity of content were affirmed. Utilizing the Partial Least Squares Structural Equation Modeling (PLS-SEM), a pilot analysis was performed. This allows the examination on the reliability as well as validity of the initial construct. The Cronbach's alpha was used in 
the pilot test. Factor analysis was also conducted on the data gathered from a sample comprising of 30 citizens with mobile marketing experience. The sample was obtained using the procedures of convenient sampling. All items appear to have value larger than the proposed cut-off of 0.70 .

\begin{tabular}{ccc} 
& Table 1: Reliability Analysis & \\
\hline VARIABLES & ITEMS \# & RELIABILITY \\
\hline Trust & 4 & .733 \\
Perceived usefulness & 4 & .831 \\
Perceived ease of use & 4 & .901 \\
Attitude toward & 4 & .801 \\
Behavioral intention & 4 & .801 \\
\hline
\end{tabular}

\section{Data Analysis}

Considering the measurement model, the assessment of the structural model was the subsequent step in the PLS Analysis; an analysis was performed towards the inner model. Hair et al.'s (2011) proposed requirements were perused. Thus, for the testing of hypotheses, the researcher employed bootstrapping to measure the significance level of the path coefficients.

The researcher applied the PLS-SEM structural model for testing the hypothesized relationships. Here, the PLS algorithm and bootstrapping algorithm in SmartPLS $2.03 \mathrm{M}$ were used. The path coefficients show high level of significance in PLS analysis. However, it should be noted that when paths are non-significant or show signs contradictory to the hypothesized direction, the earlier established hypothesis should be rejected (Hair et al., 2011).

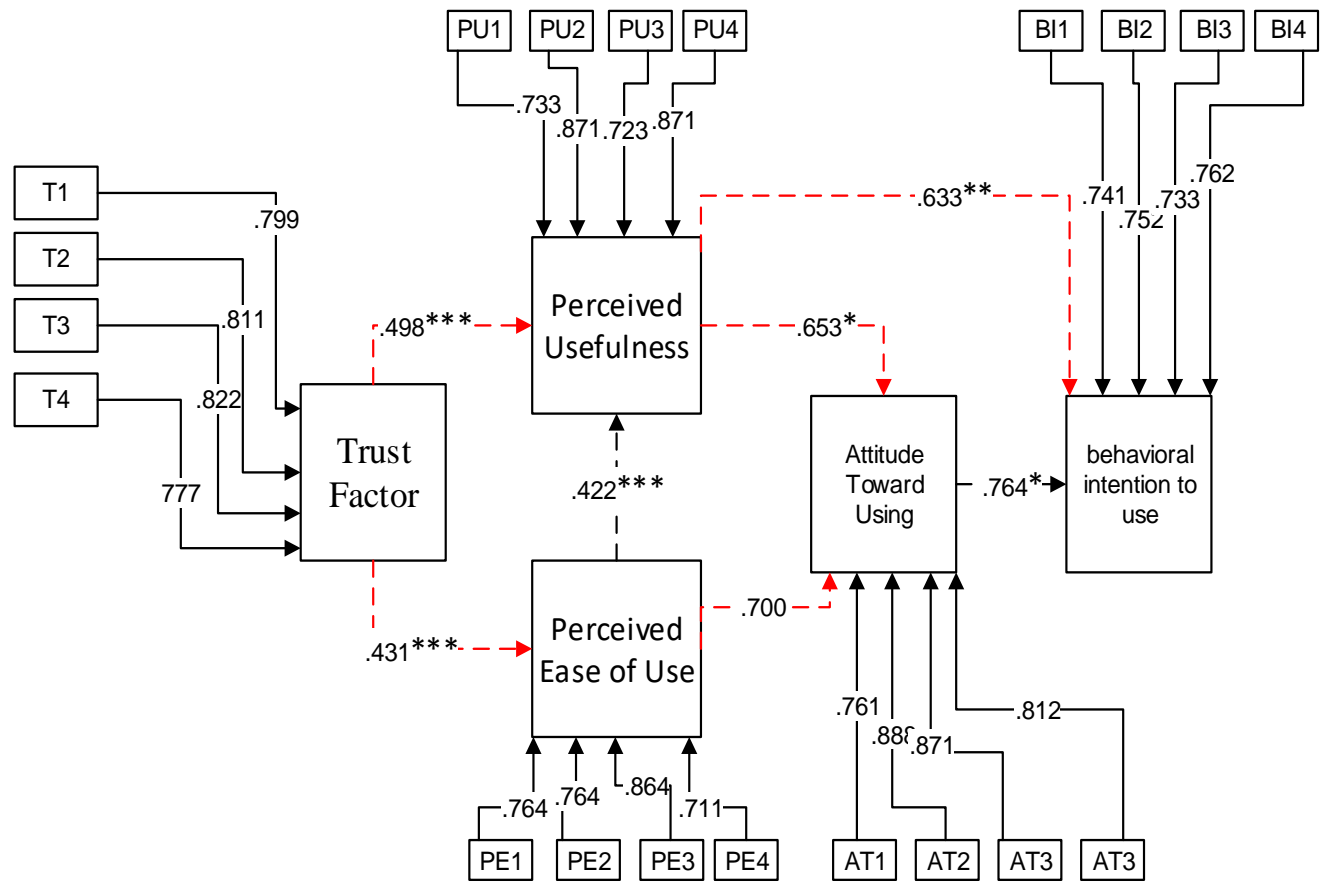

Notes: ${ }^{*} \mathrm{t}>1.960, \mathrm{p}<0.05 ;{ }^{* *} \mathrm{t}>2.576, \mathrm{p}<0.01 ;{ }^{* * *} \mathrm{t}>3.291, \mathrm{p}<0.001$

\section{Figure 3: Measurement Model}

In brief, the path coefficients for all hypotheses show significance, which means that at this level, each constructed hypothesis, is supported. Behavioral intention to use shows positive indirect linkage with the Actual system use while trustfactor also shows positive indirect linkage with the Perceived usefulness and Perceived ease of use. Likewise, the constructs of Perceived usefulness and perceived ease of use demonstrate positive indirect association with the Attitude toward. Additionally, there is positive indirect relationship between Perceived usefulness and Behavioral intention. Moreover, there is also positive indirect relationship between Attitude toward and Behavioral intention. Likewise, Behavioral 
intention has positive indirect relationships with the Actual system use. Table 2 presents the correlations for each factor in the proposed model.

Table 2: Summary of Hypotheses

\begin{tabular}{|c|c|c|c|}
\hline Hypotheses & Variable & $\beta$ & Supported \\
\hline $\mathrm{H} 1$ & Perceived usefulness & .498 & Yes \\
\hline $\mathrm{H} 2$ & 冈Perceived ease of use & .431 & Yes \\
\hline $\mathrm{H} 3$ & Perceived usefulness 冈Behavioral intention & .633 & Yes \\
\hline $\mathrm{H} 4$ & Perceived ease of use 冈Perceived usefulness & .422 & Yes \\
\hline H5 & Perceived usefulness $\otimes$ Attitude toward & .653 & Yes \\
\hline $\mathrm{H} 6$ & Perceived ease of use 冈Attitude toward & .700 & Yes \\
\hline $\mathrm{H} 7$ & 冈Behavioral intention & .764 & Yes \\
\hline
\end{tabular}

\section{Discussion and Implications}

The readiness to utilize M-marketing services among Jordanian citizens as investigated in this study particularly in terms of its extent. Here, the constructs employed and explained were those of trust, perceived usefulness, perceived ease of use, attitude toward, behavioral intention, and actual system use. As M-marketing usage among citizens should be increased, the government must tackle these factors. Data obtained were from different levels of citizens. A diverse pool of data increases the representativeness of the outcomes to the population. A model tailored to the environment of Jordan is proposed in this study. This model particularly takes in constructs from the Technology Acceptance Model (TAM). With respect to the constructs of trust, perceived usefulness, perceived ease of use, attitude toward, behavioral intention, and actual system use, there will be increase in citizens' intent to utilize Mmarketing if they are convinced that the internet would increase their efficiency in obtaining information from the government and in their interaction with the government. The intent to use of these citizens would also increase if these citizens have better control when they interact with the government. The awareness of citizens about the services that are accessible to them online should be increased and therefore, the government should adopt an awareness initiative. In addition, the government must not neglect the current technology specifically the social media. The government should thus adopt the modern medium and abandon the traditional one. As such, the government would be able to provide the citizens with real time information.

\section{I.8 Limitation}

There are a number of limitations that this study has found. First, even though there has been wide usage of M-marketing worldwide, only the M-marketing members in Jordan were considered in this research. As found in the M-marketing literature, the samples obtained from Jordan universities typically are young and highly educated. This is different from those samples used in the studies conducted in other countries. As such, the factors that were assessed and identified on the re-usage intentions of Mmarketing members are only confined to Jordan. Thus, future studies should compare their outcomes with those reported in studies in other countries.

Secondly, the modified TAM model that this study employs only tested the impacts of four independent variables and one external factor, that is, the trust variable. Thus, it would be beneficial if other factors were also investigated. As such, a comprehensive empirical research should be constructed to allow the evaluation of the effects of other factors as well.

Thirdly, this research concentrates on M-marketing usage intention with respect to products. Among industries, the most prevalent issue for them is the purchase intention of consumer following Mmarketing usage. Thus, future researchers, retailers, and manufacturers could extend this research as well in order to allow the exploration of the relationship between M-marketing usage and the continuation of purchase intention of M-marketing members. Moreover, other industries could also be the focal point in the future studies.

Lastly, this study's proposed model could also be used and extended in the future study through the addition of other constructs including the construct of service quality and computer self-efficacy. 


\section{I.9 Conclusion}

The last decade has witness the expansion of M-marketing in the developed nations. This has fascinated the developing countries especially the Middle East countries because the significant worth of being a player in the arena M- marketing is understood by these countries. Countries in the Middle East must employ the technology of Internet technology particularly in the marketing field. Unfortunately, Internet users are still lagging for nearly all countries in the Middle East particularly with respect to the varied usage of Internet. In fact, very few M- marketing sites can be found in Arab countries. The outcomes generated by this study fulfil its key objective: to increase the intention to use Arabic Mmarketing websites among Arab users. As such, the increase number of Arab e-commerce websites is expected to cause consumer to switch their online purchasing intentions towards the local Arab websites. This in turn will improve the microeconomics of Arab nations. The study offers a validated framework model for the establishment of Arabic Websites and online shopping industry. This study is also an addition to the body of knowledge on the fundamental level. The findings obtained by this study can be used as a key guideline to the academia and practitioners in their practices of business development.

\section{Reference}

A.T. Kearney (2015) Top 20 e-commerce markets of the globe. available at:

http:/ / www.consultancy.uk/news/1947/at-kearney-top-20-ecommerce-markets-of-the-globe.

Ajzen, I. and Fishbein, M. 1980. Understanding attitudes and predicting social behaviour. Prentice-Hall, 1ST, Englewood Cliffs, New Jersey.

Benassi, P. (1999). TRUSTe: An online privacy seal program. Communications of the ACM, 42(2), 56-59.

Charts, M. (2012). Newspaper Ad Expenditures Continued Fall in 11. last modified March 16.

Cheng, T. E., Lam, D. Y., \& Yeung, A. C. (2006). Adoption of internet banking: an empirical study in Hong Kong. Decision support systems, 42(3), 1558-1572.

ComReg (2014) Response to consultation and decision on price cap control for universal postal services, 18 June 2014.

Davis Fred, D. 1985. A Technology Acceptance Model for Empirically Testing New End-User Information Systems: Theory and Results, Ph. D. In Management,

Davis, F. D. 1989. Perceived usefulness, perceived ease of use, and user acceptance of information technology. MIS quarterly 319-340.

Davis, F. D. 1993. User acceptance of information technology: system characteristics,

Davis, F. D., Bagozzi, R. P. and Warshaw, P. R. 1989. User acceptance of computer technology: a comparison of two theoretical models. Management science 35(8): 982-1003.

Gefen, D. (2000). E-commerce: the role of familiarity and trust. Omega, 28(6), 725-737.

Hair, J. F., Ringle, C. M., \& Sarstedt, M. (2011). PLS-SEM: Indeed, a silver bullet. Journal of Marketing theory and Practice, 19(2), 139-152.

Hofacker, I., (2001). Algorithmical approaches to business process design. Computers $\mathcal{E}$ Operations Research, 28(13), 1253-1275.

IPSOS Open Thinking Exchange (2013). "Sociologies: The most common butterfly on earth is the social butterfly," available at http://ipsos-na.com/.

Jiang, J. C., Chen, C. A., \& Wang, C. C. (2008, August). Knowledge and trust in E-consumers' online shopping behavior. In Electronic Commerce and Security, 2008 International Symposium on (pp. 652656). IEEE.

Khalifa, M., \& Shen, K. N. (2006, July). Determinants of M-commerce Adoption: An integrated approach. In Proceedings from European and Mediterranean Conference on Information Systems EMCIS 2006.

Legris, P., Ingham, J., \& Collerette, P. (2003). Why do people use information technology? A critical review of the technology acceptance model. Information $\mathcal{E}$ anagement, 40(3), 191-204.

NPD Group., 2011. E-commerce and Consumer Electronics: Online Shopping and Purchasing". Washington: NPD Group. Nunnally, J. C., 1978. Psychometric Theory. Michigan: McGraw-Hill.

Park, T. and Salvendy, G. (2012). Emotional Factors in Advertising Via Mobile Phones. International Journal of Human-Computer Interaction, 28(9), pp.597-612. 
Rowley, J. (1996). Retailing and shopping on the Internet. International Journal of Retail \& Distribution Management, 24(3), 26-37.

Shankar, V. and Yadav, M. (2010). Emerging Perspectives on Marketing in a Multichannel and Multimedia Retailing Environment. Journal of Interactive Marketing, 24(2), pp.55-57.

Venkatesh, V., \& Morris, M. G. (2000). Why don't men ever stop to ask for directions? Gender, social influence, and their role in technology acceptance and usage behaviour. MIS quarterly, 115-139.

Venkatesh, V., Morris, M. G., Davis, G. B., \& Davis, F. D. (2003). User acceptance of information technology: Toward a unified view. MIS quarterly, 425-478.

Wang, Y. S., Wang, Y. M., Lin, H. H., \& Tang, T. I. (2003). Determinants of user acceptance of Internet banking: an empirical study. International Journal of service industry management, 14(5), 501-519.

Wu, L., \& Chen, J. L. (2005). An extension of trust and TAM model with TPB in the initial adoption of online tax: an empirical study. International Journal of Human-Computer Studies, 62(6), 784-808. 